\title{
Questioning the Impact of Journal Impact Factor on Research?
}

\author{
Tanuj Kanchan ${ }^{1}$, Kewal Krishan ${ }^{2}$
}

$\mathrm{W}$ e read with immense interest a correspondence on the impact of Journal Impact Factor (JIF) on research published in the Biomedical Journal. ${ }^{[1]}$ Impact factor, since its inception has been criticized for umpteen number of reasons. What sounded interesting from the title was that the author was touching on the issue of the effect of impact factor on our research. The content of the correspondence, however, revolves around the journal policies to increase the impact factor and related pitfalls/ manipulations. Though title to a text is author's prerogative, it should ideally be representative of the contents and conclusion drawn. ${ }^{[2]}$

We are not the great admirers of JIF, especially when it comes to assessing the researcher/scientist, but then many a times the questions raised on the utility of JIF are hypothetical and not evidence-based. We are not very sure if there is any evidence of review articles impacting the JIF or the extent of their influence on JIF, if any. Hence, the authors view that journals resort to publishing more review articles to improve their impact factor needs further elaboration. We however, agree with the author's concern on journal self-citations as a common measure adopted by the journals to improve the JIF.

Regarding the issues raised in the correspondence, we agree that JIF can be manipulated to a certain extent but then author's proposal of finding a new index that is more reliable and resistant to manipulation sounds of mere optimism. Instead, it would be better if we can propose corrective measures for the better utility of the existing JIF. Exclusion of journal self-citations while calculating the JIF can be one simple measure to combat such possible manipulation by the journals.

\section{Financial support and sponsorship}

Nil.

\section{Conflicts of interest}

There are no conflicts of interest.

\section{REFERENCES}

1. Rawat S. How is impact factor impacting our research? Biomed J 2014;37:415-6.

2. Kanchan T. Title to a text is author's prerogative. Burns 2010;36:438-9.

This is an open access article distributed under the terms of the Creative Commons Attribution-NonCommercial-ShareAlike 3.0 License, which allows others to remix, tweak, and build upon the work non-commercially, as long as the author is credited and the new creations are licensed under the identical terms.

From the ${ }^{1}$ Department of Forensic Medicine, Kasturba Medical College, Mangalore (A Constituent College of Manipal University), India; ${ }^{2}$ Department of Anthropology, Panjab University, Chandigarh, India

Received: Jan. 15, 2015; Accepted: Sep. 01, 2015

Correspondence to: Dr. Tanuj Kanchan, Department of Forensic Medicine, Kasturba Medical College, Mangalore (A Constituent College of Manipal University), India. Light House Hill Rd., Mangalore - 575 001, India. Tel.: 91-9448252394; Fax: 91-8242428183; E-mail: tanuj. kanchan@manipal.edu

DOI: $10.4103 / 2319-4170.165000$ 